Diabetologia (1995) 38: 720-725

\title{
Pharmacokinetic, insulinotropic, and glucagonostatic properties of GLP-1 [7-36 amide] after subcutaneous injection in healthy volunteers. Dose-response-relationships
}

\author{
R. Ritzel ${ }^{1,2}$, C. Ørskov ${ }^{3}$, J. J.Holst ${ }^{3}$, M. A. Nauck ${ }^{1,2}$ \\ ${ }^{1}$ Department of Medicine, Ruhr-University Bochum, Knappschafts-Krankenhaus, Bochum, Germany \\ ${ }^{2}$ Division of Gastroenterology and Endocrinology, Department of Medicine, Georg-August-University, Göttingen, Germany \\ ${ }^{3}$ Departments of Anatomy and Physiology, Panum Institute, University of Copenhagen, Denmark
}

Summary Intravenous infusions of glucagon-like peptide 1 (GLP-1) [7-36 amide] are glucose-dependently insulinotropic and glucagonostatic and normalize plasma glucose concentrations in non-insulindependent diabetic patients. It was the aim of this study to investigate whether subcutaneous GLP-1 [7-36 amide] also has an influence on insulin and glucagon secretion, and which doses are required for significant effects. Therefore, eight healthy volunteers $(24 \pm 2$ years, body mass index [BMI] $21.9 \pm 2.3 \mathrm{~kg}$ ) $\mathrm{m}^{2}$ ) were studied in the fasting state on five occasions in randomized order. Placebo $(0.9 \% \mathrm{NaCl}$ with $1 \%$ human serum albumin) or GLP-1 [7-36 amide] in doses of $0.15,0.5,1.5$ or $4.5 \mathrm{nmol} / \mathrm{kg}$ body weight (volume $1 \mathrm{ml}$ or, at the highest dose, $2 \mathrm{ml}$ ) was administered subcutaneously. An intravenous glucose bolus $(0.33 \mathrm{~g} / \mathrm{kg}$ body weight) was injected $30 \mathrm{~min}$ later. Blood was drawn for the measurement of glucose, insulin, C-peptide, GLP-1 [7-36 amide], and glucagon using specific radioimmunoassays. There were dose-related increments in GLP-1 [7-36 amide] concentrations $(p<0.0001)$. However, basal values were reached again after 90-120 min. Before glucose administration, insulin $(p<0.0001)$ and C-peptide $(p<0.0004)$ increased, whereas glucagon $(p=$ $0.0018)$ and glucose $(p<0.0001)$ decreased in a dosedependent manner. After glucose stimulation, integrated increments in insulin $(p=0.0007)$ and C-peptide $(p=0.02)$ were augmented and $\mathrm{k}_{\mathrm{G}}$-values increased $(p<0.0001)$ in a dose-related fashion. The extent of reactive hypoglycaemia was related to the GLP-1 [7-36 amide] dose. With the highest GLP-1 [7-36 amide] dose, at the time of peak plasma concentrations, most volunteers felt unwell, and nausea and vomiting were observed in four subjects. In conclusion, subcutaneous GLP-1 [7-36 amide] is also able to stimulate insulin and inhibit glucagon secretion, thereby altering glucose assimilation. However, with unmodified GLP-1 [7-36 amide], the duration of action is short, and with high doses side effects are common. [Diabetologia (1995) 38: 720-725]

Key words GLP-1 [7-36 amide], incretin, insulin, glucagon, pharmacokinetics
Glucagon-like peptide 1 [7-36 amide] is an insulinotropic hormone probably secreted from enteroglucagon-producing $\mathrm{L}$ cells in the lower gut, i.e. the

Received: 25 July 1994 and in revised form: 16 December 1994

Corresponding author: Dr. M.Nauck, Department of Medicine, Ruhr-University Bochum, Knappschafts-Krankenhaus, In der Schornau 23-25, D-44892 Bochum, Germany

Abbreviations: BMI, Body mass index; GLP-1, glucagon-like peptide-1; RIA, radioimmunoassay; RM-ANOVA, repeatedmeasures analysis of variance; GIP, gastric inhibitory polypeptide. ileum and colon/rectum [1,2]. GLP-1 [7-36 amide], together with gastric inhibitory polypeptide (GIP) from the upper gut, acts as a physiological incretin hormone $[3,4]$. In pharmacological concentrations, exogenous GLP-1 [7-36 amide or 7-37] raised insulin and lowered glucagon concentrations also in noninsulin-dependent diabetic (NIDDM) patients $[5,6]$. By these mechanisms, plasma glucose was normalized by intravenous GLP-1 [7-36 amide] in NIDDM patients with secondary failure of sulphonylurea treatment within 3-4 h [7]. Therefore, it has been suggested to use GLP-1 [7-36 amide] or GLP-1 [7-37] (which has an identical action profile in rats [8] and 
humans [9]) in the therapy of NIDDM patients $[6,7$, 10].

The aim of the present study was to characterize the pharmacokinetic, insulinotropic and glucagonostatic actions of GLP-1 [7-36 amide] administered subcutaneously into healthy volunteers. Preliminary results have been communicated in abstract form [11].

\section{Subjects, materials and methods}

Study protocol. The study protocol was approved by the ethics committee of the medical faculty of the Georg-August-University, Göttingen prior to the study. Written informed consent was obtained from all participants.

Subjects. Eight normal subjects (two female, six male) were studied. They were $24 \pm 2$ years old, height was $178 \pm 7 \mathrm{~cm}$, body weight was $70 \pm 10 \mathrm{~kg}$, and body mass index (BMI) was $21.9 \pm 2.3 \mathrm{~kg} / \mathrm{m}^{2}$. They had no personal or family history of diabetes or gastrointestinal diseases and none took any medication except for oral contraceptive pills.

All the subjects were studied on five occasions. In randomized order, in a single-blind fashion, placebo $(0.9 \% \mathrm{NaCl}$ with $1 \%$ human serum albumin) or GLP-1 [7-36 amide] in doses of $0.15,0.5,1.5$, or $4.5 \mathrm{nmol} / \mathrm{kg}$ body weight were administered in the morning after an overnight fast.

Peptides. Synthetic GLP-1 [7-36 amide] was purchased from Saxon Biochemicals GmbH, Hannover, Germany. The same lot number was used as in previous studies (GLP-1 [736 amide]: PGAS 242, Lot ZE 865, net peptide content $79.3 \%)[4,5,7]$. The peptide was dissolved in $0.9 \% \mathrm{NaCl}$ containing $1 \%$ human serum albumin (Merieux, Norderstedt, Germany), filtered through $0.2-\mu \mathrm{m}$ nitrocellulose filters (Millipore, Bedford, Mass., USA) and stored frozen at $-30^{\circ} \mathrm{C}$ as previously described. Net peptide content rather than gross weight was used for dose calculations. HPLC profiles (provided by the manufacturer) showed that the preparation was more than $99 \%$ pure (single peak coeluting with appropriate standards). Samples were analysed for bacterial growth (standard culture techniques) and for pyrogens (Limulus amebocyte lysate endo-LAL, Chromogenix AB, Mölndal, Sweden). No bacterial contamination was detected. Endotoxin concentrations in the GLP-1 [7-36 amide] stem solutions always were under $0.03 \mathrm{EU} / \mathrm{ml}$.

Experimental procedures. Two forearm veins were punctured with a teflon cannula (Moskito 123, 18 gauge; Vygon, Aachen, Germany), and kept patent using $0.9 \% \mathrm{NaCl}$ (one for blood sampling and the other one for glucose injections).

After drawing basal blood specimens, at 0 min, GLP-1 [736 amide] was administered subcutaneously into the periumbilical region. The injected volume was $1 \mathrm{ml}$ per $85 \mathrm{~kg}$ body weight (and $2 \mathrm{ml}$ in the case of the highest GLP-1 [736 amide] dose). Preliminary experiments had demonstrated a peak of GLP-1 [7-36 amide] concentrations after approximately $30 \mathrm{~min}$. Therefore, at $30 \mathrm{~min}$, an intravenous glucose bolus was administered within $1 \mathrm{~min}(0.33 \mathrm{~g} / \mathrm{kg}$ body weight, $40 \%$ weight/volume; Braun Melsungen, Melsungen, Germany). Blood was drawn at the intervals shown in Figures 1, 2 and 3.

Blood specimens. Blood was drawn into heparinized tubes (immunoreactive [YR] insulin and C-peptide measurements).
A sample was stored in $\mathrm{NaF}$ (Microvette CB 300; Sarstedt, Nümbrecht, Germany) for the measurement of glucose. For glucagon and GLP-1 [7-36 amide] measurements blood was drawn into tubes containing EDTA and aprotinin (Trasylol; 20000 kallikrein inhibition units $/ \mathrm{ml}, 200 \mu \mathrm{l}$ per $10 \mathrm{ml}$ blood; Bayer AG, Leverkusen, Germany). After centrifugation, plasma for hormone analyses was kept frozen at $-30^{\circ} \mathrm{C}$.

Laboratory determinations. Glucose was measured using a glucose oxidase method with a Glucose Analyser 2 (Beckman Instruments, Munich, Germany). Plasma IR-insulin and C-peptide were determined using commercial radioimmunoassay kits (Insulin RIA 100; Pharmacia, Freiburg, Germany; RIAmat C-peptide, Byk-Sangtec Diagnostika, Dietzenbach, Germany), with human insulin and C-peptide as standard.

IR-GLP-1 was determined in ethanol-extracted plasma as previously described [12], using antiserum 89390 (final dilution $1: 150000$ ) and synthetic GLP-1 [7-36 amide] for tracer preparation and as standard. Recovery of GLP-1 [736 amide] standards after alcohol extraction was $75 \pm 8 \%$. The experimental detection limit (two standard deviations over samples not containing GLP-1 [7-36 amide]) was less than $5 \mathrm{pmol} / \mathrm{l}$. Antiserum 89390 binds proglucagon-derived peptides containing the amidated carboxy-terminus of GLP-1 [7-36 amide], thereby being relatively specific for GLP-1 [736 amide] [13]. Plasma samples with expected high concentrations were diluted $1: 10$ with assay buffer before analysis. Pancreatic glucagon was assayed in ethanol-extracted plasma using antibody 4305 [14].

Each patient's set of plasma samples was assayed at the same time to avoid errors due to inter-assay variation.

Symptoms. During the experiments, the participating volunteers were observed and frequently asked about their state of well-being. Their answers were recorded using an open questionnaire.

\section{Statistical analysis}

Subject characteristics are reported as mean $\pm S D$, experimental results are reported as mean $\pm S E M$. Integration was carried out according to the trapezoidal rule. The glucose assimilation coefficient $\left(\mathrm{k}_{\mathrm{G}}\right.$-value of Conrad et al. [15]) was calculated from the slope of the natural logarithm of glucose concentrations measured 5, 10, and 15 min after the glucose bolus. Significances of differences were tested using repeated measurement analysis of variance (RM-ANOVA; NCSS Version 5.01, Kaysville, Utah, USA). If a significant interaction of treatment and time was documented $(p<0.05)$, values at single time points were compared by one-way analysis of variance. If again significant differences were found $(p<0.05)$, Student's $t$-test (paired analyses) was performed to compare each GLP-1 [7-36 amide] dose with placebo. For contingency table analysis (side effects present/absent), a chi-square-test was used. A two-sided $p$ value $<0.05$ was taken to indicate significant differences.

\section{Results}

There was a dose-related increment of GLP-1 [736 amide] plasma concentrations after subcutaneous injection (Fig. 1). Even the lowest dose raised plasma concentrations to peak values of $280 \pm 52 \mathrm{pmol} / \mathrm{l}$ after $15 \mathrm{~min}$, and with higher doses, even higher con- 

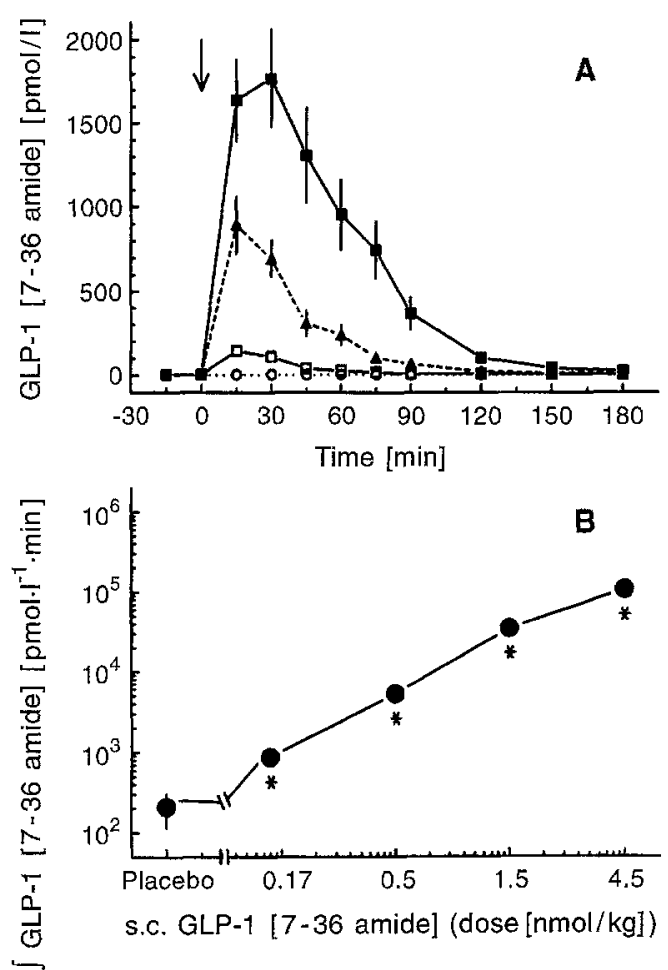

Fig. 1 (A, B). GLP-1 [7-36 amide] plasma concentrations (A) and integrated incremental GLP-1 [7-36 amide] plasma concentrations (B) after the subcutaneous administration of placebo $(O)$ or GLP-1 [7-36 amide] at a dose of $0.5(\square), 1.5(\boldsymbol{A})$, and 4.5 ( $) \mathrm{nmol} / \mathrm{kg}$ in normal subjects. The lowest dose $(0.15 \mathrm{nmol} / \mathrm{kg})$ has been omitted from panel A for reasons of clarity. Mean \pm SEM. Repeated measures ANOVA indicated a significant difference $(p<0.0001)$ between the time courses of GLP-1 [7-36 amide] concentrations in panel A (interaction of experiment and time). One-way ANOVA indicated $p<0.0001$ for the integrated values presented in panel $B$. * Significant difference to the placebo study (by Student's $t$ test, $p<0.05$ )

centrations were observed. Peak concentrations occurred at 15-30 min, and basal values were recorded again after $90-120 \mathrm{~min}$. The area under the plasma concentration curve was linearly related to the dose administered (Fig. 1 B).

Time courses of plasma glucose and insulin concentrations are presented in Figure 2 (A and B). After the intravenous glucose bolus, more than in the basal state, GLP-1 [7-36 amide] significantly augmented the insulin secretory response (time course of C-peptide concentrations not shown).

Plasma glucagon (Fig. 2C) was dose-dependently suppressed by GLP-1 [7-36 amide] even before the administration of glucose. Glucose uniformly further reduced plasma glucagon concentrations. After reactive reductions in plasma glucose concentrations (Fig. 2A), approximately 30-45 min after the glucose bolus, there was a dose-related reactive increment in glucagon levels (Fig. 2C).

Dose-response relationship for actions of subcutaneous GLP-1 [7-36 amide] in the basal state are shown in Figure 3. Glucose was slightly, but dose-de-
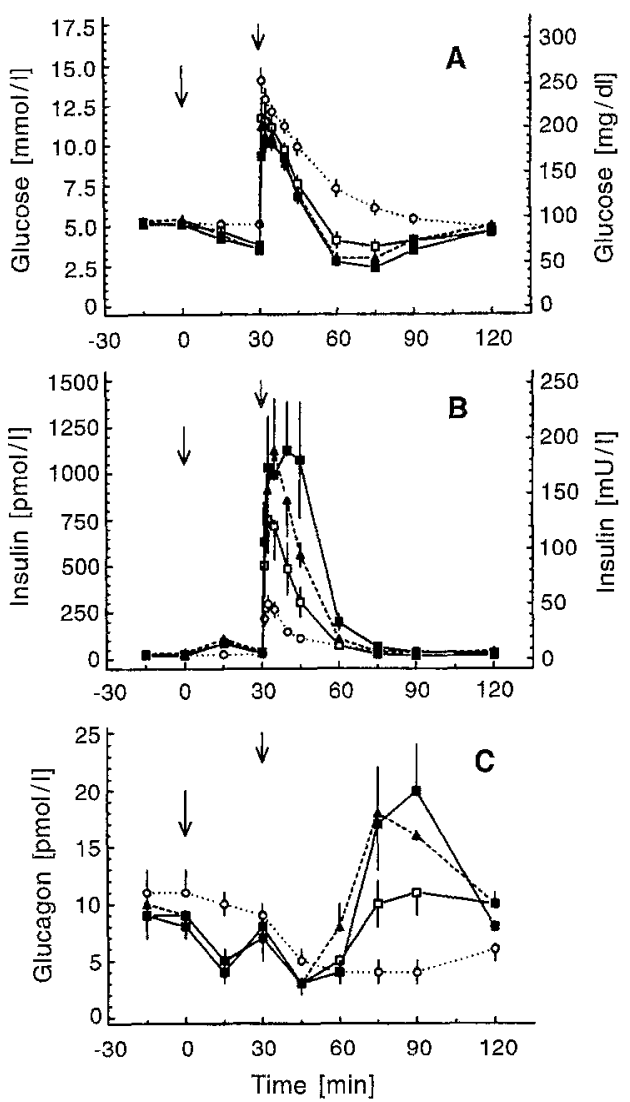

Fig.2 (A-C). Plasma glucose (A), insulin (B) and glucagon (C) concentrations in the time course of experiments with subcutaneous administrations of placebo (O) or GLP-1 [736 amide] at a dose of $0.5(\square), 1.5(\Delta)$, and $4.5(\mathbf{\square}) \mathrm{nmol} / \mathrm{kg}$ (arrow), $30 \mathrm{~min}$ later followed by intravenous glucose administration (arrow), in normal subjects. The lowest dose $(0.15 \mathrm{nmol} / \mathrm{kg})$ has been omitted for reasons of clarity. Mean $\pm S E M$. Repeated measures ANOVA indicated a significant difference between the time courses of glucose, insulin and glucagon ( $p<0.0001$, respectively) (interaction of experiment and time)

pendently reduced (to $4.2 \pm 0.5 \mathrm{mmol} / 1$ at the highest dose, $p=0.0019)$. Insulin $(p<0.0001)$ and C-peptide $(p=0.0004)$ were stimulated to a maximum of approximately three- to four-fold over basal values, and glucagon was dose-dependently reduced by up to $45-55 \%$ of basal concentrations $(p=0.0018)$.

After glucose injection (Fig. 2), integrated incremental insulin $(p=0.0007)$ and C-peptide $(p=$ 0.0198 ) was dose-dependently augmented by subcutaneous GLP-1 [7-36 amide] (details not shown). This led to a faster glucose assimilation as demonstrated by greater $\mathrm{k}_{\mathrm{G}}$-values (Fig. 4).

Subjective experiences of the participating volunteers indicated an altered state of well-being at the higher doses of GLP-1 [7-36 amide] in most subjects studied (Table 1). Specifically, complaints included vertigo, paraesthesias, hyperhydrosis, and chills. Nausea was common at higher doses, and in half of the subjects vomiting occurred at the time of peak plasma concentrations $(22 \pm 8 \mathrm{~min}$ after GLP 1 [7- 

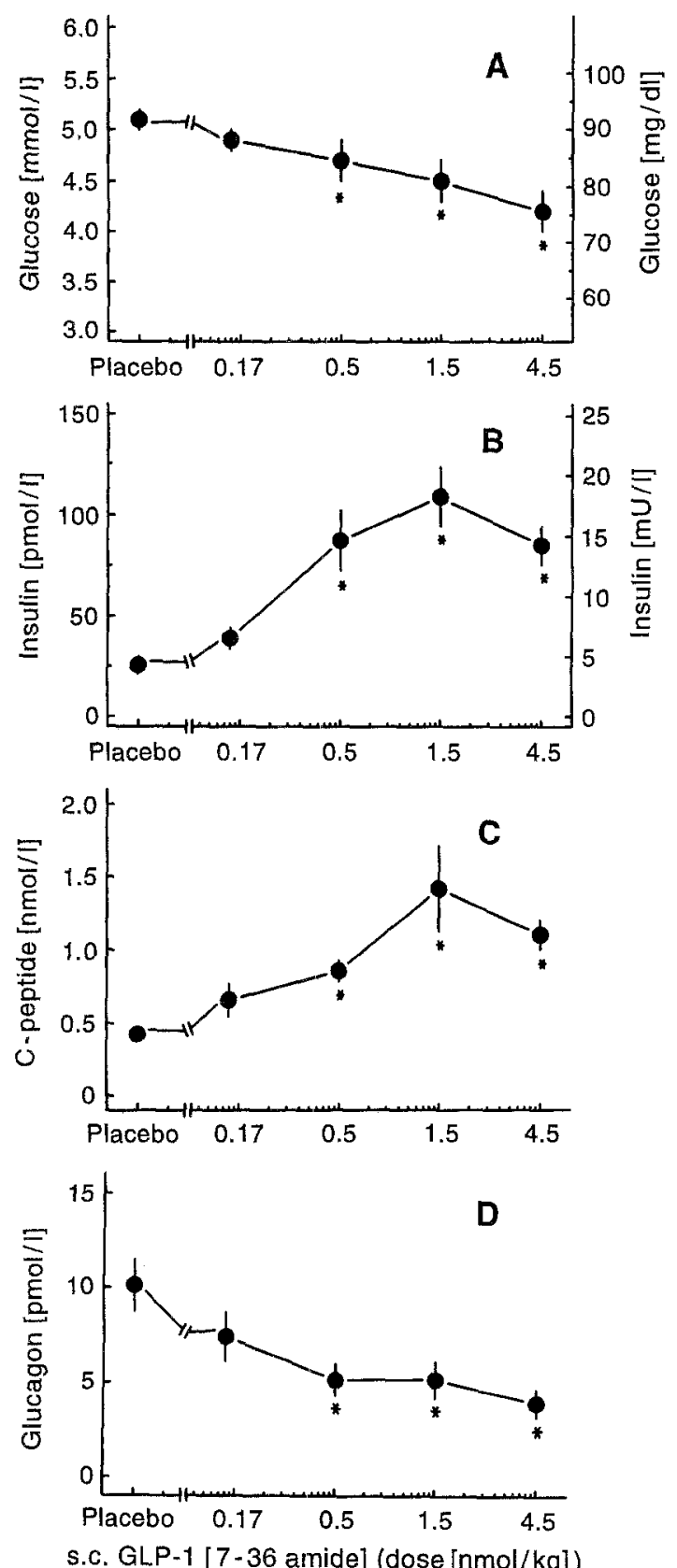

Fig. 3 (A-D). Dose-response relationship for plasma glucose (A), insulin (B) C-peptide (C) and glucagon (D) concentrations 15 min after the subcutaneous administration of placebo or GLP-1 [7-36 amide] in normal subjects. Mean \pm SEM. One-way ANOVA indicated significant differences with $p$ values of 0.0019 (glucose), $<0.0001$ (insulin), 0.0004 (C-peptide) and 0.0018 (glucagon), respectively. * Significant difference to the placebo study (by Student's $t$-test, $p<0.05$ )

36 amide] administration, compare Fig. 1) with the highest dose (Table 1).

\section{Discussion}

The results of the present study indicate that qualitatively similar effects can be achieved with subcutaneous GLP-1 [7-36 amide] as have previously been

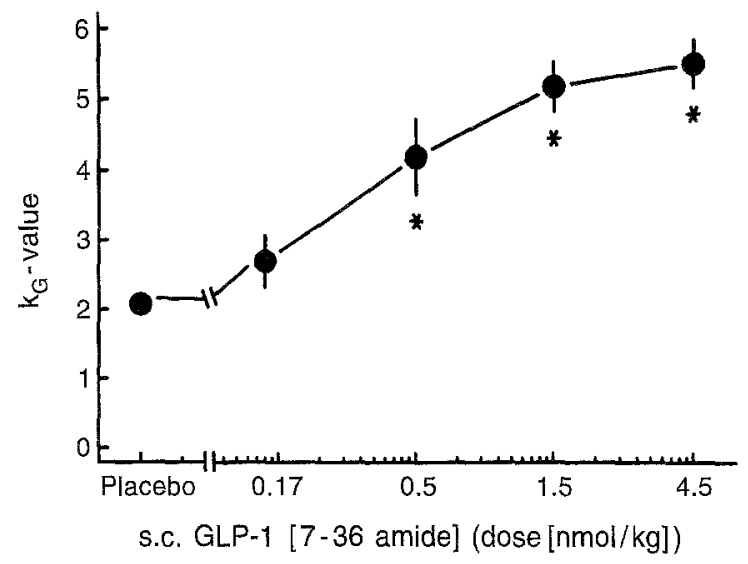

Fig. 4. Dose-response relationship for the glucose assimilation coefficient $\left(\mathrm{k}_{\mathrm{G}}\right.$-value of Conard et al. [15]) after the subcutaneous administration of placebo or GLP-1 [7-36 amide] in normal subjects. Mean \pm SEM. One-way ANOVA indicated a $p$ value of $<0.0001$. * Significant difference to the placebo study (by Student's $t$-test, $p<0.05$ )

observed with intravenous infusions of GLP-1 [736 amide], both in normal subjects $[3,4]$ and in NIDDM patients $[5-7,10]$. There was a slight stimulation of insulin secretion and a clear reduction of plasma glucagon in the basal state, which led to a slight reduction in plasma glucose concentrations, far short of hypoglycaemia (Figs. 2 and 3). Effects on insulin secretion were more marked after raising plasma glucose concentrations (Fig.2), confirming the potentiating interaction between GLP-1 [7-36 amide] and glucose on insulin secretion $[3,4,7,8]$.

It is interesting to note that during the phase of reactive hypoglycaemia after the glucose bolus injection (at approximately $60-75 \mathrm{~min}$ on the time scale in Figs. 1 and 2) there was a counterregulatory glucagon response (Fig. 2) despite elevated concentrations of GLP-1 [7-36 amide] after the two highest subcutaneous doses (Fig.1). This suggests that GLP-1 [736 amide] does not impair counterregulatory increments of pancreatic glucagon, although it can reduce glucagon levels in the fasting state $[3,5,7,9]$, i.e. at euglycaemia. However, counterregulatory hormone responses and glucose metabolism during experimentally controlled hypoglycaemia should be studied under the influence of GLP-1 [7-36 amide].

Since the insulinotropic action of GLP-1 [736 amide $][5,7,10]$ and of its analogue, GLP-1 [737] $[6,9]$, is preserved in NIDDM patients, a mode of administration has to be looked for that could be used in therapeutic trials exploiting the "antidiabetogenic" [10] actions of GLP-1 [7-36 amide]. Subcutaneous administration is one obvious way, and has been used in preliminary studies involving small numbers of patients [16]. In these studies, much smaller GLP-1 [7-36 amide] doses were used (15 or $25 \mathrm{nmol}$ ) than were found most effective in the present study. These and our data show that in principle 
Table 1. Frequency of side effects of subcutaneously administered GLP-1 [7-36 amide] in eight normal subjects

\begin{tabular}{|c|c|c|c|c|c|c|}
\hline \multirow[t]{2}{*}{ Type of disturbance } & \multicolumn{6}{|c|}{ Dose of GLP-1 [7-36 amide] administered [ $\mathrm{nmol} / \mathrm{kg}$ body weight] } \\
\hline & Placebo & 0.15 & 0.5 & 1.5 & 4.5 & $p$-value \\
\hline Altered state of well-being & 0 & 0 & 2 & 5 & 8 & $<0.0001$ \\
\hline Paraesthesia & 0 & 0 & 0 & 1 & 1 & 0.53 \\
\hline Hyperhydrosis & 0 & 0 & 0 & 1 & 2 & 0.22 \\
\hline Thermal sensations & 0 & 0 & 1 & 1 & 1 & 0.71 \\
\hline Vomiting ${ }^{\mathrm{a}}$ & 0 & 0 & 0 & 0 & 4 & 0.0014 \\
\hline
\end{tabular}

Vomiting occurred at $22 \pm 8 \mathrm{~min}$ after subcutaneous GLP-1 [7-36 amide] administrations. For plasma concentrations, see

Figure 1. $p$-values are approximate, because the number of

subcutaneous administrations of GLP-1 [7-36 amide] have the expected effects, but that the pharmacokinetic behaviour is rather unsuitable, because there is a rapid peak followed by a rapid decay in plasma concentrations after the subcutaneous injection of unmodified GLP-1 [7-36 amide] in aqueous solution (Fig. 1). The fact that the highest dose of GLP-1 [736 amide] was injected in a higher volume ( 2 instead of $1 \mathrm{ml}$ ) did not appear to influence the pharmacokinetic behaviour to any greater extent as judged by the time to peak and other characteristics of the plasma concentration profile (Fig. 1).

In line with this pharmacokinetic behaviour, our preliminary studies in NIDDM patients have shown a significant reduction in plasma glucose concentrations within the first $2 \mathrm{~h}$ after the subcutaneous administration of GLP-1 [7-36 amide] $(1.5 \mathrm{nmol} / \mathrm{kg}$ body weight), but the effect is moderate (Nauck MA, Wollschläger D, Willms B, unpublished observations) in comparison to previous results using intravenous infusions [5-7]. It should also be noted that overall higher doses of GLP-1 [7-36 amide] appear necessary to raise plasma concentrations when administered subcutaneously as compared to intravenously. The calculated clearance rate (dose divided by incremental response of plasma concentrations) after subcutaneous administration was between $212 \pm 48$ (lowest dose) and $50 \pm 7 \mathrm{ml} \cdot \mathrm{kg}^{-1} \cdot \mathrm{min}^{-1}$ (highest dose), which is higher than that during intravenous infusion (approximately $12-14 \mathrm{ml} \cdot \mathrm{kg}^{-1}$. $\left.\min ^{-1}[3,4,7]\right)$ and, therefore, may indicate incomplete delivery of GLP-1 [7-36 amide] into the vascular compartment. In addition, partial degradation might occur also in subcutaneous tissue, as has been demonstrated after prolonged incubation in plasma via dipeptidyl-peptidase $I V$ [17]. This would not alter GLP-1 immunoreactivity, but could reduce biological effects of subcutaneous GLP-1 [7-36 amide]. As a consequence, GLP-1 [7-36 amide] preparations or analogues with retarded absorption kinetics, less susceptibility to proteolytic degradation and prolonged action should be investigated.
Side effects of GLP-1 [7-36 amide] administration leading to plasma concentrations closer to the normal physiological range have never been described. In the present series of experiments, very high plasma concentrations (Fig. 1) occurred, and at the higher doses, serious side effects were observed (Table 1). Since the participants were not informed about the dose of GLP-1 [7-36 amide] studied on a particular day, the symptoms can be causally related to high circulating levels of GLP-1 [7-36 amide], especially since they occurred approximately at the time point of peak plasma concentrations. In this respect it is of interest that cerebral specific binding sites for GLP-1 [736 amide] have been described [18-20]. Although their normal function is not well characterized and although there is no clear concept to explain how GLP1. [7-36 amide] could cross the blood-brain-barrier, it has to be suggested that interactions of circulating GLP-1 [7-36 amide] with these receptors may be responsible for the side effects observed. In any case, therapeutic regimens of administering GLP-1 [736 amide] should avoid plasma concentrations higher than $500 \mathrm{pmol} / \mathrm{l}$, especially as a near-complete inhibition of gastric emptying has been observed with exogenous GLP-1 [7-36 amide] in NIDDM patients (M.A.Nauck, J.Werner, B.Willms, C.Ørskov, J. J.Holst, unpublished observations). In normal subjects, this effect is observed also, but not to the same extent [21].

GLP-1 [7-36 amide]-effects may be different when examined with a mixed meal than when using intravenous glucose to stimulate insulin secretion, as in the present study. In a postprandial situation, effects on gastric emptying may predominate (M.A. Nauck, J.Werner, B.Willms, C. Ørskov, J.J.Holst, unpublished observations), which will greatly reduce substrate stimulation of insulin secretion.

In conclusion, subcutaneous GLP-1 [7-36 amide] administered to normal subjects, stimulates insulin secretion in a glucose-dependent fashion, lowers glucagon concentration in the basal state, and accelerates glucose assimilation after an intravenous glu- 
cose bolus. However, the duration of action of unmodified GLP-1 [7-36 amide] injected subcutaneously is short, and does not appear suitable for therapeutic trials in NIDDM patients. It may be worthwhile to develop GLP-1 [7-36 amide] preparations or analogues with a more retarded action, which should more fully exploit the therapeutic potential of GLP1 [7-36 amide].

Acknowledgements. The excellent technical assistence of Ms. S. Bierkamp, A. Bernhard, and L. Albæk is gratefully acknowledged. This study was supported by the Deutsche Forschungsgemeinschaft, Bonn 2 (Bad Godesberg), grant Na 203/ 2-2, by the Danish Medical Research Council, and by the Novo Nordisk Foundation.

\section{References}

1. Ørskov C (1992) Glucagon-like peptide-1, a new hormone of the entero-insular axis. Diabetologia 35: 701-711

2. Creutzfeldt W, Nauck M (1992) Gut hormones and diabetes mellitus. Diabetes Metab Rev 8: 149-177

3. Kreymann B, Ghatei MA, Williams G, Bloom SR (1987) Glucagon-like peptide 1 7-36: a physiological incretin in man. Lancet II: 1300-1304

4. Nauck M, Bartels E, Ørskov C, Ebert R, Creutzfeldt W (1993) Additive insulinotropic effects of exogenous synthetic human gastric inhibitory polypeptide and glucagonlike peptide 1 [7-36 amide] infused at near-physiological insulinotropic hormone and glucose concentrations. J Clin Endocrinol Metab 76: 912-917

5. Nauck MA, Heimesaat MM, Ørskov C, Holst JJ, Ebert R, Creutzfeldt W (1993) Preserved incretin activity of glucagon-like peptide 1 (GLP-1) [7-36 amide] but not of synthetic human gastric inhibitory polypeptide (GIP) in patients with type 2 diabetes mellitus. J Clin Invest 91: 301307

6. Nathan DM, Schreiber E, Fogel H, Mojsov S, Habener JF (1992) Insulinotropic action of glucagon-like-peptide-I-(737) in diabetic and nondiabetic subjects. Diabetes Care 15: 270-276

7. Nauck MA, Kleine N, Ørskov C, Holst JJ, Willms B, Creutzfeldt W (1993) Normalization of fasting hyperglycaemia by exogenous glucagon-like peptide 1 [7-36 amide] in type 2 (non-insulin-dependent) diabetic patients. Diabetologia 36: 741-744

8. Weir GC, Mojsov S, Hendrick GK, Habener JF (1989) Glucagonlike peptide I (7-37) actions on endocrine pancreas. Diabetes 38: 338-342
9. Ørskov C, Wettergren A, Holst JJ (1993) Biological effects and metabolic rates of glucagonlike peptide-1 7-36 amide and glucagonlike peptide-1 7-37 in healthy subjects are indistinguishable. Diabetes 42: 658-661

10. Gutniak M, Ørskov C, Holst JJ, Ahren B, Efendic S (1992) Antidiabetogenic effect of glucagon-like peptide-1 (7-36) amide in normal subjects and patients with diabetes. $\mathrm{N}$ Engl J Med 326: 1316-1322

11. Ritzel R, Ørskov C, Holst JJ, Nauck M (1994) Pharmakokinetische, insulinotrope und glucagonostatische Eigenschaften von GLP-1 [7-36 Amid] nach subkutaner Injektion bei stoffwechselgesunden Probanden. Dosis-Wirkungs-Beziehungen Diabetes Stoffw 3 [Suppl]: 158 (Abstract)

12. Ørskov C, Holst JJ (1987) Radio-immunoassays for glucagon-like peptides 1 and 2 (GLP-1 and GLP-2). Scand J Clin Lab Invest $47:$ 165-174

13. Ørskov C, Rabenhøj L, Wettergren A, Kofod H, Holst JJ (1994) Tissue and plasma concentrations of amidated and glycine-extended glucagon-like peptide 1 in humans. Diabetes 43: $535-539$

14. Holst JJ (1982) Evidence that peak II GLI or enteroglucagon is identical to the C-terminal sequence (residues 3369) of glicentin. Biochem J 207: 381-388

15. Conard V, Franckson JRM, Bastenie PA, Kestens J, Kovaks L (1953) Etude critique du triangle d'hyperglycémie intraveneux chez l'homme normal et détermination d'un coefficient d'assimilation glucidique. Arch Int Pharmacodyn 93: $277-286$

16. Gutniak MK, Holst JJ, Linde B, Efendic S (1994) Subcutaneous injection of the incretin hormone Glucagon-like Peptide 1 abolishes postprandial glycemia in NIDDM. Diabetes Care 17: 1039-1044

17. Mentlein R, Gallwitz B, Schmidt WE (1993) Dipeptidylpeptidase IV hydrolyses gastric inhibitory polypeptide, glucagon-like peptide-1 (7-36) amide, peptide, hiostidine methionine and is responsible for their degradation in human serum. Eur J Biochem 214: 829-835

18. Hoosein NM, Gurd RS (1984) Human glucagon-like peptides 1 and 2 activate rat brain adenylate cyclase. FEBS Lett 178: 83-86

19. Kanse SM, Kreymann B, Ghatei MA, Bloom SR (1988) Identification and characterization of glucagon-like peptide 1 7-36 amide-binding sites in the rat brain and lung. FEBS Lett 241: 209-212

20. Seifert H, Gallwitz B, Schmidt WE, Creutzfeldt W (1990) Mapping of ${ }^{125}$ I-GLP I $(7-36)-\mathrm{NH}_{2}$ binding sites in rat brain. Digestion 46 [Suppl 1]: 104 (Abstract)

21. Wettergen A, Schjoldager B, Mortensen PE, Myhre J, Christiansen J, Holst JJ (1993) Truncated GLP-1 (proglucagon 87-107-amide) inhibits gastric and pancreatic functions in man. Dig Dis Sci 38: 665-673 